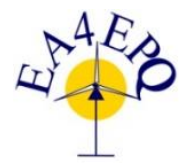

International Conference on Renewable Energies and Power Quality (ICREPQ’18)

Salamanca (Spain), $21^{\text {st }}$ to $23^{\text {rd }}$ March 2018

Reneuble Energy and Pourer Quality. Toumal (RE\&PQJ)

ISSN 2172-038 X, No.16 March 2018

\title{
Electrical Distribution Systems' Reconfiguration Considering Distributed Generation: Implementation and Comparison of Metaheuristic Tools
}

\author{
W. R. Faria ${ }^{1}$, M. E. De Oliveira ${ }^{1}$, H. X. Rocha ${ }^{1}$, L. G. W. Da Silva ${ }^{1}$ \\ ${ }^{1}$ Federal Institute of Education, Science and Technology of Goiás at Itumbiara, Researches in Energy Systems Group - \\ NuPSE \\ Itumbiara-GO, Brazil \\ Phone/Fax number: +55 64 21035600, e-mail: wandryrodrigues@ hotmail.com
}

\begin{abstract}
The classic distribution systems operate as radial systems, which means that the power flows in only one way: from the substations to the consumers and there is only one active electrical circuit connecting those two points. There are, however, tie switches (normally open switches) that, when closed, change the electrical circuit allowing the loads to be supplied by a different feeder or branch. Besides the reliability incensement, by correctly using the tie switches it is possible to reduce the technical power losses and improve the consumer's voltage magnitude. The distribution systems' reconfiguration is a very complex problem due to the infinitude of possibilities, thus a common solution is to apply metaheuristic routines. This work presents the implementation and comparison of two metaheuristic routines developed to solve the reconfiguration problem in distribution systems considering the insertion of distributed generation. The paper presents the results of 16 and 33 bus test systems.
\end{abstract}

Keywords: Network Reconfiguration; Distributed Generation; Multi-objective Metaheuristic Optimization; Distribution Systems; Backward Forward Power Flow

\section{Introduction}

Electrical Distribution Systems are, in general, planned and built as weakly meshed networks, however, they operate as radial systems, which means the power flows always in a single direction - from the substations to the loads - and there is a single electrical circuit connecting these points. To guarantee the system's radiality, some switches must be closed (sectionalizing switches), and others must be open (tie switches). The maneuvering of the tie and sectionalizing switches is called system reconfiguration [1].

To assure the optimal operation point of a distribution system, or yet in the event of a fault and a partial system isolation is needed, the reconfiguration network study is applied. On this evaluation, a solution with the fewer unsupplied consumers and minimum power loss, respecting the system's limitations, is sought. The distribution network electrical circuit's is changed by maneuvering mechanical switches placed on the system [1]. However, there are several switches in the distribution system which makes the evaluation of every possible configuration a very complex problem. Due to the infinity of possible reconfigurations, manual technics to evaluate the circuits cannot be applied. A common approach to solve the problem is the employment of computational tools.

In general, computational routines use exact methods to solve a problem. The algorithms based on exact solving verifies every possibility to select the best response. However, due to the huge number of possibilities when it comes to network reconfiguration, these methods are proven inefficient - they demand too much time and computational effort. An alternative method to solve the problem is to use metaheuristic computational routines. This method seeks optimized not-exact solutions which reduce the time and computational effort [1], [2].

The network reconfiguration is a well-spread topic, nevertheless, the distribution systems have been changing over the last few years due to the insertion of distributed generators. According to [3], [4], inserting distributed generation (DG) to the classic distribution system changes its traditional passive nature and the reevaluation of maintenance procedures, security and measurement conditions, and possible changing of the system's configuration, which is this paper's subject, becomes essential.

Two computational tools for determining optimized topologies to operate distribution systems with or without distributed generation are presented in this paper. The employed method uses the electrical variables, which are the result of a power flow routine, as input data to metaheuristic routines.

The metaheuristic routines also can be used as support tools to allocate DG in distribution networks. Tests have been conducted using IEEE's test systems. The results of 16 and 33 bus test systems are listed in section 4 and present improvements on the system's voltage magnitude and power loss.

\section{Backward/Forward Sweep}

Solving the network reconfiguration problem requires the comparison between different system's topologies, the variables used to establish the best configuration are power loss and voltage magnitudes; both are results of a power flow routine.

There are many power flow methods, however, some of them cannot be applied to distribution systems due to the networks radiality, high $\boldsymbol{R} / \boldsymbol{X}$ ratio and unbalanced phases. Amongst the methods that can be used, the backward- 
forward sweep [1], [5] is predominant. The tool is an iterative routine based on Kirchhoff's current and voltage laws. The process has three steps: nodal currents calculation, branch currents calculation (backward sweep) and nodal voltage calculation (forward sweep).

\section{A. Nodal Currents Calculation}

The nodal current is calculated from the power injection and nodal voltage data. In addition, it is considered the reactive power from shunt elements connected to each node. The nodal current is calculated as:

$$
I_{i}^{(k)}=\left(\frac{s_{i}}{V_{i}^{(k-1)}}\right)^{*}-Y_{i} V_{i}^{(k-1)}
$$

$V_{i}^{(k-1)}$ is the voltage magnitude at node $i$ on the $(k-$ 1)-th iteration;

$Y_{i}$ is the sum of shunt elements connected to the node $i$

$S_{i}$ is the injected power at the node $i$;

$I_{i}^{(k)}$ is the calculated current at node $i$ on the $k$-th iteration.

\section{B. Nodal Currents Calculation}

Based on the calculated nodal current, the branch currents are calculated. The current in each branch is given by the sum of the current in each node connected downstream as shown in figure 1.

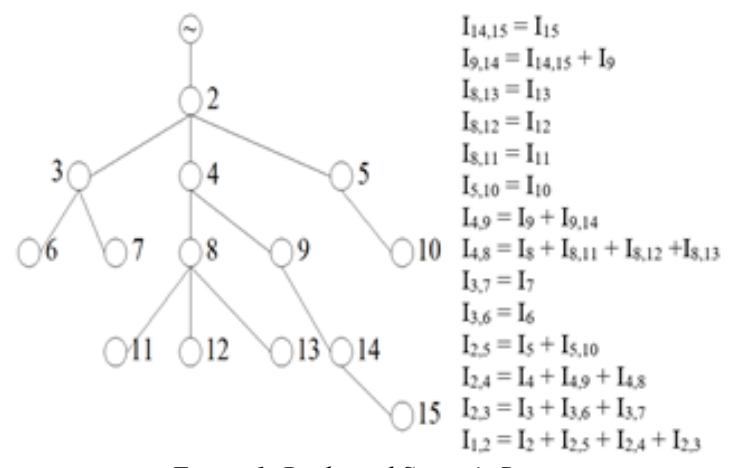

Figure 1. Backward Sweep's Representation.

\section{Nodal Currents Calculation}

The nodal voltage is calculated based on the branch's current and on the circuit's electrical impedance as shown in the equation below:

$$
V_{i}^{k}=V_{i-1}^{k}-z_{i} I_{i}^{(k-1)}
$$

$V_{i}^{k}$ is the voltage at node $i$ on iteration $k$ (starting on node 2, since node 1 is the substation and therefore has controlled voltage);

$V_{(i-1)}$ is the node connected upstream to $i$

$z_{i}$ is the electrical impedance of the line connecting the nodes $i$ and $(i-1)$;

$I_{i}^{(k-1)}$ is the current on the branch that connects nodes $i$ and ( $i$ 1) on the iteration $(k-1)$.

\section{Iterative Process}

The voltage calculated on the Forward Sweep is used as feedback on (1) changing, therefore, the nodal current, which will change the branch current and furthermore the nodal voltage. The iterative process continues until the stop criterium is reached.

The stop criteria adopted on this tool is based on power mismatches. Using the calculated voltage and current, the power on each node $\left(S_{i}^{k}\right)$ is calculated using the following equation:

$$
S_{i}^{k}=\left(V_{i}^{k} * I_{i}^{k}\right)-Y_{i}\left|V_{i}^{(k)}\right|^{2}
$$

The real and reactive power mismatches, $\Delta P_{i}^{k}$ and $\Delta Q_{i}^{k}$ respectively, are then calculated as presented in (4) and (5).

$$
\begin{aligned}
& \Delta P_{i}^{k}=\operatorname{Re}\left(S_{i}^{k}-S_{i}\right) \\
& \Delta Q_{i}^{k}=\operatorname{Im}\left(S_{i}^{k}-S_{i}\right)
\end{aligned}
$$

The mismatches are then compared to a predefined error $\mathcal{E}$. Once the routine converges, the data are exported and can be used to compare the system's efficiency.

\section{Algorithms Implementation}

Acknowledging that for each possible topology the electrical variables (especially voltage magnitude and power loss) chance systemwide, by applying a power flow routine to every possible configuration would determine the optimal operation point. This is how the exact methods based routines operate, the problem is that it would take too much time and computational effort, due to the elevated number of configuration possibilities in a real distribution system.

The metaheuristic routines have a reduced search space [1][2], reducing also time and computational effort, on the other hand, the solutions are not exact, which means even though the solutions are optimized, it may not be the best solution. This paper presents the implementation of two metaheuristic routines to solve the network reconfiguration problem: one of them based on Genetic Algorithm and the second uses Tabu Search. Both routines are able to solve the problem considering the insertion of GDs at any node.

\section{A. Genetic Algorithm Implementation}

Genetic Algorithms (GA) are part of a stochastic metaheuristic class based on biology that uses genetic concepts [6]. The use of GA to solve the reconfiguration problem is proposed in many works such as [1][2][7][8]. The codification strategy used in this tool is described in [1].

According to [6][9], one of the most important parts when implementing a GA is the fitness function's definition. In this case, the fitness function is the power flow routine and the analysis of active power loss and voltage magnitude. Given the problem's multiobjective characteristic - it is desirable both the power loss reduction and voltage magnitude increase - an ordering strategy tool named 
NSGA-II was implemented; the routine is presented in [6] [10].

The chromosomes are evaluated by its power flow results and combined among themselves using a binary tournament. The new solutions are evaluated, and the best results are selected by the NSGA-II routine to continue on the population of solutions. The process continues until the iteration limit, called generations, is reached. The tool's flowchart is shown in figure 2 .

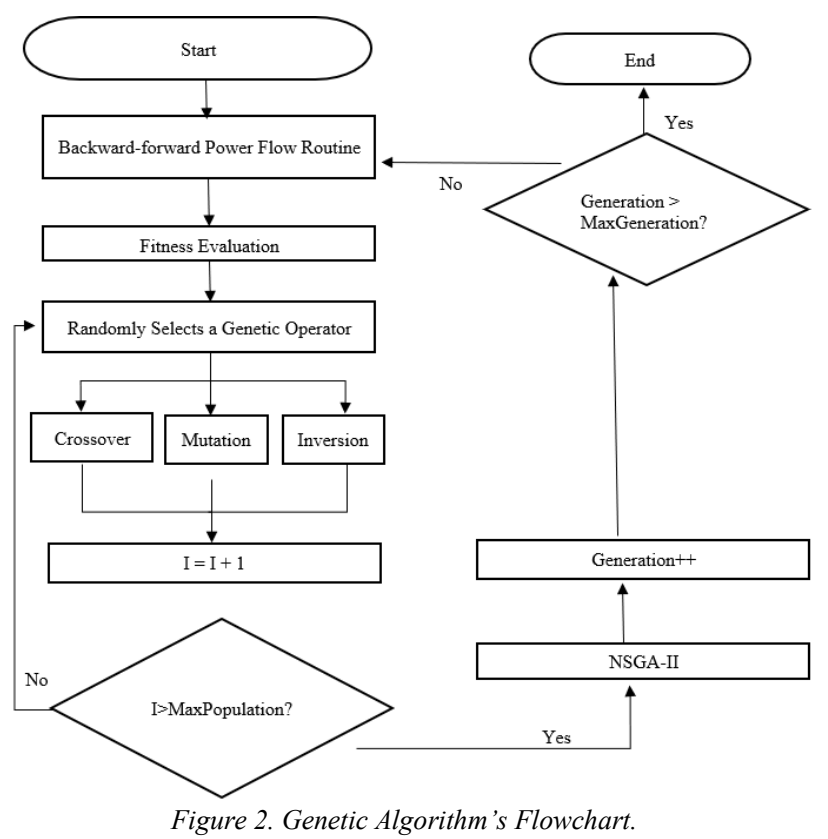

\section{B. Tabu Search Implementation}

Tabu Search (TS) is a heuristic algorithm that, based on specific considerations about the problem it was created to solve, delivers satisfying results more efficiently than a local search. The TS is initialized like a local search algorithm. However, the search's progression is an iterative process that depends on the neighbor solutions [11], [12], [13] until the stop criterium is reached.

For every current solution, a neighborhood search is conducted. The search space is defined on the code, it is important to highlight that a small search area results in time and computational reduction at the cost of the solution's quality. Amongst the neighbor solutions, the best is selected as the current solution and the process continues until the stop criterium.

The implemented Tabu Search's neighborhood search is described in [14]. The neighborhood's evaluation is based on the power flow results. If one of the neighboring solutions is better than the current solution it becomes the current solution, even if it is on the tabu list. On the event of none of the neighboring solutions being better than the current solution, the best solution among them is selected to substitute the current solution. The tool's flowchart is presented in figure 3 .

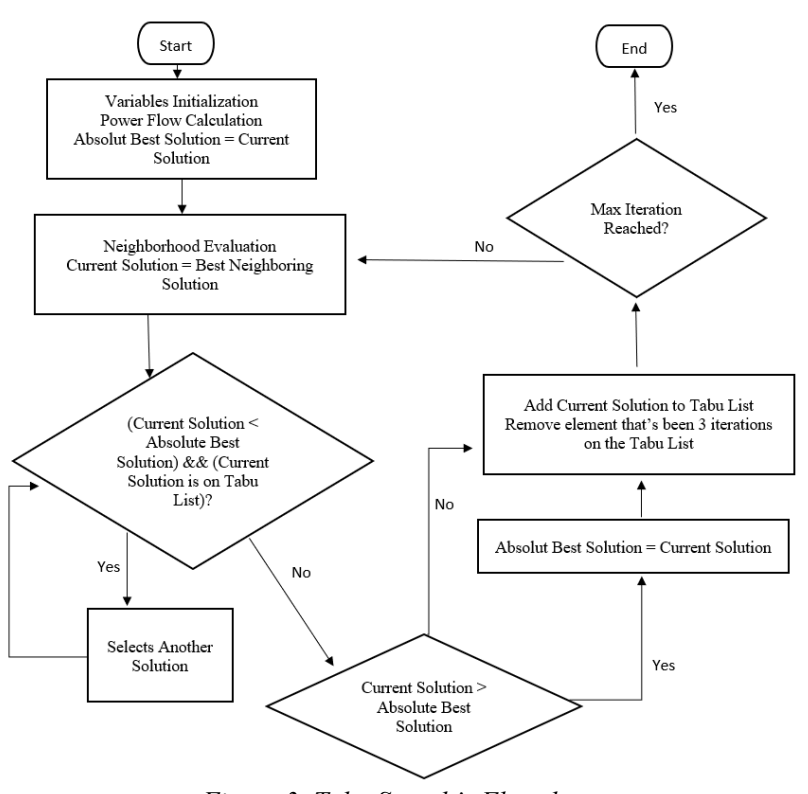

Figure 3. Tabu Search's Flowchart.

\section{Fitness Function}

Among the quality indicators of a distribution system, one of the most important is the voltage magnitude. For medium voltage (MV) systems the critical values are, usually, 0.95 and $1.03 \mathrm{pu}$. Another factor that is prioritized by the electric companies is the active power losses due to the circulation of electrical current through the conductors. The fitness function considers both power loss and critical voltage (highest and lowest) of every topology. The poor results are penalized using the NSGA-II routine, which guaranties the "survival" of the best solutions and, when combined to the crowding distance routine, ensures that the most different chromosomes are kept in the population.

The values of power loss and voltage magnitude are given by the power flow routine described in section 2 .

\section{Results}

The algorithms were tested with literature material and this section presents the results of IEEE 16 and 33 bus systems. The computational tools suggest new configurations aiming power loss reduction and voltage magnitude improvement.

The distributed generator model used to perform the simulations was a PV module with a 0.95 lagging fixed power factor.

\section{A. 16 bus test system}

The system's data is found in [15] and presented in table 1, the system's diagram is shown in figure 4 .

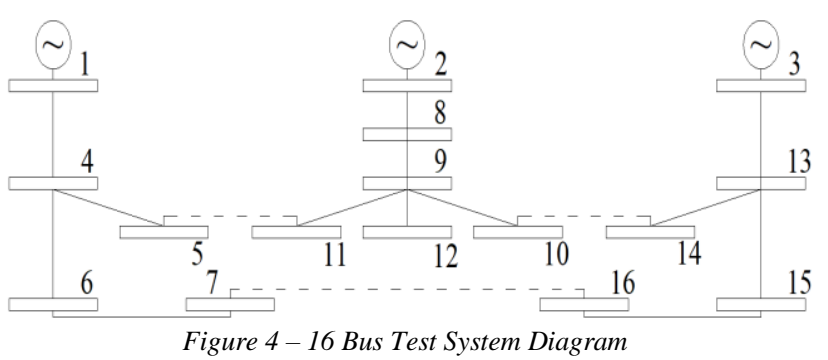

Figure 4-16 Bus Test System Diagram 


\begin{tabular}{|c|c|c|c|c|c|}
\hline $\begin{array}{c}\text { Bus } \\
\text { Origin - } \\
\text { Destiny }\end{array}$ & $R(p u)$ & $X(p u)$ & $\begin{array}{c}\text { Destiny Bus } \\
P(M W)\end{array}$ & $\begin{array}{c}\text { Destiny Bus } \\
Q(\text { MVAR })\end{array}$ & $\begin{array}{c}\text { Destiny Bus } \\
\text { Capacitor } \\
(\text { MVAR })\end{array}$ \\
\hline $1-4$ & 0.075 & 0.1 & 2 & 1.6 & - \\
\hline $4-5$ & 0.08 & 0.11 & 3 & 1.5 & 1.1 \\
\hline $4-6$ & 0.09 & 0.18 & 2 & 0.8 & 1.2 \\
\hline $6-7$ & 0.04 & 0.04 & 1.5 & 1.2 & - \\
\hline $2-8$ & 0.11 & 0.11 & 4 & 2.7 & - \\
\hline $8-9$ & 0.08 & 0.11 & 5 & 3 & 1.2 \\
\hline $8-10$ & 0.11 & 0.11 & 1 & 0.9 & - \\
\hline $9-11$ & 0.11 & 0.11 & 0.6 & 0.1 & 0.6 \\
\hline $9-12$ & 0.08 & 0.11 & 4.5 & 2 & 3.7 \\
\hline $3-13$ & 0.11 & 0.11 & 1 & 0.9 & - \\
\hline $13-14$ & 0.09 & 0.12 & 1 & 0.7 & 1.8 \\
\hline $13-15$ & 0.08 & 0.11 & 1 & 0.9 & - \\
\hline $15-16$ & 0.04 & 0.04 & 2.1 & 1 & 1.8 \\
\hline $5-11$ & 0.04 & 0.04 & - & - & - \\
\hline $10-14$ & 0.04 & 0.04 & - & - & - \\
\hline $7-16$ & 0.09 & 0.12 & - & - & - \\
\hline \multicolumn{7}{|c|}{ Table 1-16 Bus Test System Data } \\
\hline
\end{tabular}

The reconfiguration results using both tools are presented in table 2.

\begin{tabular}{|c|c|c|c|}
\hline & $\begin{array}{l}\text { Original } \\
\text { System }\end{array}$ & $\begin{array}{c}G A \\
\text { reconfiguration }\end{array}$ & $\begin{array}{c}T S \\
\text { reconfiguration }\end{array}$ \\
\hline $\begin{array}{c}\text { Tie } \\
\text { Switches }\end{array}$ & $\begin{array}{c}S_{5,11} S_{10,14} \\
S_{16,7}\end{array}$ & $S_{9,8} S_{14,13} S_{16,7}$ & $S_{5,11} S_{8,10} S_{16,7}$ \\
\hline $\begin{array}{l}\text { Critical } \\
\text { Voltage }\end{array}$ & $0.9718 p u$ & $0.9743 p u$ & $0.9743 p u$ \\
\hline Power Loss & $0.0045 \mathrm{pu}$ & $0.0035 \mathrm{pu}$ & $0.0043 p u$ \\
\hline $\begin{array}{c}\text { Simulation } \\
\text { Time }\end{array}$ & & 291 seconds & 60 seconds \\
\hline
\end{tabular}

Table $2-16$ Bus Test System Reconfiguration Results

Even though the GA based algorithm presents better results, the routine takes longer than the TS code to converge. On larger systems, the convergence time may become a problem.

\section{B. 33 bus test system}

The system's data is presented in table 3 and its diagram on figure 5.

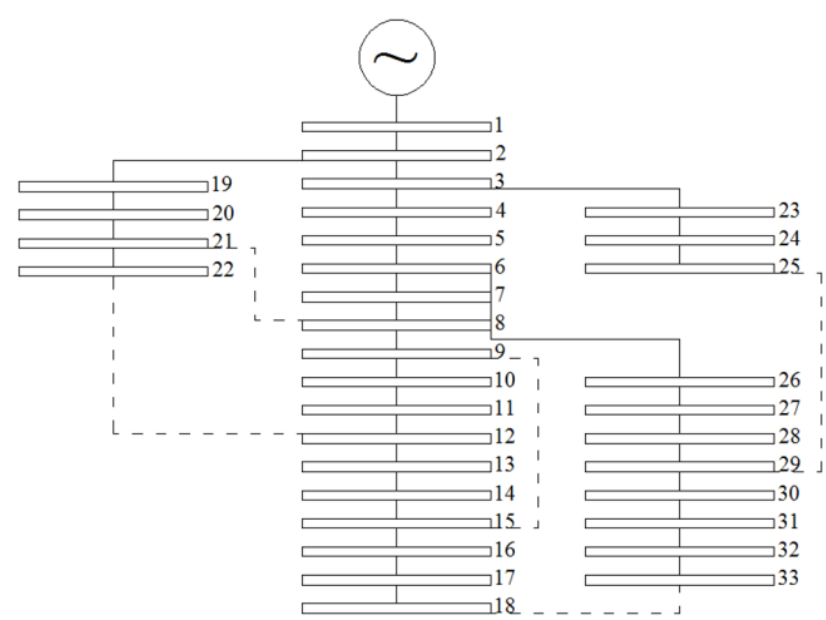

Figure 5 - 33 Bus Test System Diagram

\begin{tabular}{|c|c|c|c|c|c|}
\hline $\begin{array}{c}\text { Origin } \\
\text { Bus }\end{array}$ & $\begin{array}{c}\text { Destiny } \\
\text { Bus }\end{array}$ & $R(p u)$ & $X(p u)$ & $\begin{array}{c}\text { Destiny Bus } \\
P(p u)\end{array}$ & $\begin{array}{c}\text { Destiny Bus } \\
Q(p u)\end{array}$ \\
\hline 1 & 2 & 0.00058 & 0.00029 & 0.00 & 0.00 \\
\hline 2 & 3 & 0.00308 & 0.00157 & 0.10 & 0.06 \\
\hline 3 & 4 & 0.00228 & 0.00116 & 0.09 & 0.04 \\
\hline 4 & 5 & 0.00238 & 0.00121 & 0.12 & 0.08 \\
\hline 5 & 6 & 0.00511 & 0.00441 & 0.06 & 0.03 \\
\hline 6 & 7 & 0.00117 & 0.00386 & 0.06 & 0.02 \\
\hline 7 & 8 & 0.00444 & 0.00147 & 0.20 & 0.10 \\
\hline 8 & 9 & 0.00643 & 0.00462 & 0.20 & 0.10 \\
\hline 9 & 10 & 0.00651 & 0.00462 & 0.06 & 0.02 \\
\hline 10 & 11 & 0.00123 & 0.00041 & 0.06 & 0.02 \\
\hline 11 & 12 & 0.00234 & 0.00081 & 0.05 & 0.03 \\
\hline 12 & 13 & 0.00916 & 0.00721 & 0.06 & 0.04 \\
\hline 13 & 14 & 0.00338 & 0.00445 & 0.06 & 0.04 \\
\hline 14 & 15 & 0.00369 & 0.00328 & 0.12 & 0.08 \\
\hline 15 & 16 & 0.00466 & 0.00340 & 0.06 & 0.01 \\
\hline 16 & 17 & 0.00804 & 0.01074 & 0.06 & 0.02 \\
\hline 17 & 18 & 0.00457 & 0.00358 & 0.06 & 0.02 \\
\hline 2 & 19 & 0.00102 & 0.00098 & 0.09 & 0.04 \\
\hline 19 & 20 & 0.00938 & 0.00846 & 0.09 & 0.04 \\
\hline 20 & 21 & 0.00256 & 0.00298 & 0.09 & 0.04 \\
\hline 21 & 22 & 0.00442 & 0.00585 & 0.09 & 0.04 \\
\hline 3 & 23 & 0.00282 & 0.00192 & 0.09 & 0.04 \\
\hline 23 & 24 & 0.00560 & 0.00442 & 0.09 & 0.05 \\
\hline 24 & 25 & 0.00559 & 0.00437 & 0.42 & 0.20 \\
\hline 6 & 26 & 0.00127 & 0.00065 & 0.42 & 0.20 \\
\hline 26 & 27 & 0.00177 & 0.00090 & 0.06 & 0.03 \\
\hline 27 & 28 & 0.00661 & 0.00583 & 0.06 & 0.03 \\
\hline 28 & 29 & 0.00502 & 0.00437 & 0.06 & 0.02 \\
\hline 29 & 30 & 0.00317 & 0.00161 & 0.12 & 0.07 \\
\hline 30 & 31 & 0.00608 & 0.00601 & 0.20 & 0.60 \\
\hline 31 & 32 & 0.00194 & 0.00226 & 0.15 & 0.07 \\
\hline 32 & 33 & 0.00213 & 0.00331 & 0.21 & 0.10 \\
\hline 8 & 21 & 0.01248 & 0.01248 & 0.06 & 0.04 \\
\hline 9 & 15 & 0.01248 & 0.01248 & - & - \\
\hline 12 & 22 & 0.01248 & 0.01248 & - & - \\
\hline 18 & 33 & 0.00312 & 0.00312 & - & - \\
\hline 25 & 29 & 0.00312 & 0.00312 & - & - \\
\hline & & Table3-33 Bus Test System Data & \\
\hline
\end{tabular}

The reconfiguration results using the Genetic Algorithm and Tabu Search routines are shown in table 4.

\begin{tabular}{|c|c|c|c|}
\hline & Original System & $\begin{array}{c}\text { GA } \\
\text { Reconfiguration }\end{array}$ & $\begin{array}{c}\text { TS } \\
\text { Reconfiguration }\end{array}$ \\
\hline Tie Switches & $\begin{array}{c}S_{15,9} S_{29,25} S_{8,21} \\
S_{12,22} S_{18,33}\end{array}$ & $\begin{array}{c}S_{14,15} S_{29,25} \\
S_{7,8} S_{12,22} S_{17,18}\end{array}$ & $\begin{array}{c}S_{13,14} S_{26,27} \\
S_{8,21} S_{12,22} S_{18,33}\end{array}$ \\
\hline $\begin{array}{l}\text { Critical } \\
\text { Voltage }\end{array}$ & $0.9632 p u$ & $0.9795 p u$ & $0.9711 p u$ \\
\hline Power Loss & $0.1647 p u$ & $0.1180 \mathrm{pu}$ & $0.1479 p u$ \\
\hline $\begin{array}{c}\text { Simulation } \\
\text { Time }\end{array}$ & & 3000 seconds & 350 seconds \\
\hline
\end{tabular}

Table 4 - 33 Bus Test System Reconfiguration Results 
To simulate a network with distributed generation, a $0.1 \mathrm{pu}$ generator - about $2,7 \%$ of the system's load - was inserted in different nodes. The modified systems' results - with and without reconfiguration - are shown in table 5.

\begin{tabular}{|c|c|c|c|c|}
\hline & $\begin{array}{c}\text { System with } \\
\text { DG on bus } \\
10\end{array}$ & $\begin{array}{c}\text { Reconfigured } \\
\text { System with } \\
\text { DG on bus } \\
10\end{array}$ & $\begin{array}{c}\text { System with } \\
\text { DG on bus } \\
18\end{array}$ & $\begin{array}{l}\text { Reconfigured } \\
\text { System with } \\
\text { DG on bus } 18\end{array}$ \\
\hline Tie Switches & $\begin{array}{cc}S_{15,9} & S_{29,25} \\
S_{8,21} & S_{12,22} \\
S_{18,33}\end{array}$ & $\begin{array}{c}S_{15,9} S_{26,27} \\
S_{8,21} S_{12,22} \\
S_{30,31}\end{array}$ & $\begin{array}{cc}S_{15,9} & S_{29,25} \\
S_{8,21} & S_{12,22} \\
S_{18,33}\end{array}$ & $\begin{array}{c}S_{11,12} S_{24,25} \\
S_{8,21} S_{12,22} \\
S_{29,30}\end{array}$ \\
\hline $\begin{array}{l}\text { Critical } \\
\text { Voltage }\end{array}$ & $0.9236 p u$ & $0.9571 p u$ & $0.9293 p u$ & $0.9779 p u$ \\
\hline Power Loss & $0.0983 \mathrm{pu}$ & $0.0737 p u$ & $0.1111 \mathrm{pu}$ & $0.0367 p u$ \\
\hline
\end{tabular}

The results presented in table 5 show that changing the generator's insertion node affects both the power loss and voltage magnitude. Hence, the importance of having a tool to analyze and suggest the best node for a distributed generator's insertion.

As prior mentioned, there is a simulation time discrepancy when comparing the Genetic Algorithm and Tabu Search routines - the second method is about 10x faster.

The TS has a reduced search area due to the neighborhood definition, that reduces the number of power flow calculations per iteration and consequently the simulation time; however, reducing the neighborhood decreases the solution's quality.

To reduce the simulation time difference between the codes, two alterations were made to the Genetic Algorithm:

1) Population reduction;

2) Creating a second stop criterium: if there is no solution improvement in 10 generations, the iterative process stops.

The results, when applying the modified codes to the 16 and 33 bus test system, are shown in table 6 and 7 .

\begin{tabular}{|c|c|c|c|c|}
\hline & $\begin{array}{c}15 \text { elements } \\
\text { GA with } \\
\text { Second } \\
\text { Stop } \\
\text { Criterium }\end{array}$ & $\begin{array}{c}\text { 6 elements } \\
\text { GA }\end{array}$ & $\begin{array}{c}\text { GA with } \\
\text { Second } \\
\text { Stop } \\
\text { Criterium }\end{array}$ \\
\hline $\begin{array}{c}\text { Critical } \\
\text { Voltage }\end{array}$ & $0.9716 \mathrm{pu}$ & $0.9716 \mathrm{pu}$ & $0.9716 \mathrm{pu}$ & $0.9716 \mathrm{pu}$ \\
\hline Power Loss & $0.0035 \mathrm{pu}$ & $0.0035 \mathrm{pu}$ & $0.0035 \mathrm{pu}$ & $0.0035 \mathrm{pu}$ \\
\hline $\begin{array}{c}\text { Simulation } \\
\text { Time }\end{array}$ & 291 seconds & 189 seconds & 152 seconds & 89 seconds \\
\hline
\end{tabular}

For a small network, such as 16 bus test system, the optimal point is easily found. Therefore, reducing the population does not imply in a reduction of the result's quality, as shown in table 6 . When it comes to larger systems, however, applying the modifications to the GA's code reduces the output's quality, as presented in table 7 .

\begin{tabular}{|c|c|c|c|c|}
\hline & $\begin{array}{c}\text { 50 elements } \\
\text { GA }\end{array}$ & $\begin{array}{c}25 \text { elements } \\
\text { GA with } \\
\text { Second } \\
\text { Stop } \\
\text { Criterium }\end{array}$ & $\begin{array}{c}15 \text { elements } \\
\text { GA }\end{array}$ & $\begin{array}{c}\text { GA with } \\
\text { Second } \\
\text { Stop } \\
\text { Criterium }\end{array}$ \\
\hline $\begin{array}{c}\text { Critical } \\
\text { Voltage }\end{array}$ & $0.9795 \mathrm{pu}$ & $0.9792 \mathrm{pu}$ & $0.9787 \mathrm{pu}$ & $0.9771 \mathrm{pu}$ \\
\hline Power Loss & $0.1180 \mathrm{pu}$ & $0.1334 \mathrm{pu}$ & $0.1251 \mathrm{pu}$ & $0.1388 \mathrm{pu}$ \\
\hline $\begin{array}{c}\text { Simulation } \\
\text { Time }\end{array}$ & $\begin{array}{c}3000 \\
\text { seconds }\end{array}$ & $\begin{array}{c}1200 \\
\text { seconds }\end{array}$ & 420 seconds & 280 seconds \\
\hline
\end{tabular}

Using 15 elements population when solving the 33 bus reconfiguration allows the GA to compete with the TS in terms of simulation time, as presented in the table's 7 two most-right columns.

\section{Conclusion}

Comparing the methodologies, the TS provides solutions demanding less computational effort and time. There is, however, a quality improvement when analyzing the results provided by the GA. Thus, the GA based program could be used in planning situations, while the TS routine may be applied to operational situations.

Another point to emphasize is the importance of correctly choosing a node to insert DG, given its effects on the voltage magnitude and power losses.

The tool presented in this paper can be applied to fully operational electrical distribution systems with or without distributed generation, providing changes to the system's topology aiming energy quality improvement. The program can also be employed as a subsidiary tool to the planning of GDs insertion stipulating the best location to do so.

\section{Acknowledgement}

The authors thank the Instituto Federal de Educação, Ciência e Tecnologia de Goiás, CNPq and NuPSE for all the support.

\section{References}

[1] Z. Ming, B. Pengxiang, L. Jian, Z. Wenyuan. "An Improved Genetic Algorithm for Distribution System Reconfiguration”. International Conference on Power System Technology, vol. 3, pp. 1734-1738, 2002.

[2] R. J. Sarfi, M. M. A. Salama, A. Y. Chikhani, "A Survey of the State of the Art in Distribution System Reconfiguration for System Loss Reduction”. Electric Power System Research, vol. 31, pp. 61-70, 1994.

[3] K. Divya, S. Srinivasan. "Optima Siting and Sizing of DG in Radial Distribution System and Identifying Fault Location in Distribution System Integrated with Distributed Generation". International Conference on Advanced Computing and Communication Systems, Coimbatore, 2016.

[4] J. J. Grainger, W. D. Stevenson, Power System Analysis. New York: McGraw-Hill, 1994.

[5] B. Pengxiang, L. Jian, Z. Wenyan. "Convergence of branch current based distribution power flow method". Journal of Xian Jiaotong University, vol. 35, no.4, pp.343-346, 2001.

[6] H. X. Rocha, S. Peretta, G. F. M. Lima, R. S. Boaventura, L. G. Marques, K. Yamanaka. "Statistical Decision Support for Fitness Function Formulation to Multi-Objective Evolutionary Algorithms: a Case Study on Computer Automated Exterior Lighting Design". 
[7] K. Nara, A. Shiose, M. Kitagawa. "Implementation of genetic algorithm for distribution systems loss minimum reconfiguration". IEEE Transactions on Power System, vol.7, no.3, pp.1044-1051, 1992.

[8] L. Jiansheng, D. You-man, Z. Bo-ming. "Hybrid flow pattern and its application in network reconfiguration". Proceedings of the CSEE, vol. 21, no.1, pp.57-62, 2001.

[9] D. E. Goldberg. "Genetic Algorithms in Search, Optimization and Machine Learning”. Addison-Wesley Longman, 1989.

[10] H. Rocha, I. S. Peretta, G. F. M. Lima, L. G. Marques, K, Yamanaka. "Exterior Lighting Computer-Automated Design Based on MultiCriteria Parallel Evolutionary Algorithm: Optimized Designs for Illumination Quality and Energy Efficiency". Expert Systems with Applications 45, pp. 208-222, 2016.

[11] H. Mori, Y. Ogita. "A Parallel Tabu Search Based Approach to Optimal Network Reconfigurations for Service Restoration in Distribution Systems". Proc. Of the 2002 International Conference on Control Applications, vol. 2, pp.814-819, 2002.

[12] D. Zhang, Z. Fu, L. Zhang. "An Improved TS Algorithm for LossMinimum Reconfiguration in Large_Scale Distribution Systems". Int. J. Electrical Power Systems Research, vol. 77, no. 5-6, pp. 685694, 2007.

[13] A. Y. Abdelaziz, F. M. Mohamed, S. F. Mekhamer, M. A. L. Badr. "Distribution System Reconfiguration Using a Modified Tabu Search Algorithm". Int. J. Electrical Power Systems Research, vol. 80, no. 8, pp. 943-953, 2010.

[14] N. Xiong, H. Cheng, L. L. Yao, M. Bazargan. "Switch Group Based Tabu Search Algorithm for Distribution Network Reconfiguration". International Conference on Deregulation and Restructuring and Power Technologies, pp. 820-822, 2008.

[15] S. Cinvalar, J. J. Grainger, H. Yin, S. S. H. Lee. "Distribution Feeder Reconfiguration for Loss Reduction". IEEE Transactions on Power Delivery, vol. PWRD-3, pp. 1217-1223, 1988. 